\title{
Time of ovulation in goats (Capra hircus) induced to superovulate with PMSG
}

\author{
A. W. N. Cameron, K. M. Battye and A. O. Trounson \\ Centre for Early Human Development, Monash Medical Centre, 246 Clayton Road, Clayton, \\ Victoria 3168, Australia
}

\begin{abstract}
Summary. The timing of ovulation in feral goats treated with 1200 i.u. PMSG $\pm 50 \mu \mathrm{g}$ GnRH was studied by repeated laparoscopy. Experiment 1 established that superovulation began as early as $30 \mathrm{~h}$ after withdrawal of progestagen-impregnated sponges and was not completed at $54 \mathrm{~h}$ if goats received PMSG alone. GnRH synchronized ovulation, leading to $91 \%$ of ovulations appearing between 36 and $48 \mathrm{~h}$ after sponges were withdrawn. Experiment 2 established that superovulation continued until up to $77 \mathrm{~h}$ in goats treated only with PMSG. The stress of repeated laparoscopy appeared to delay or abolish ovulation in some females. The mean ( \pm s.e.) ovulation rate was greater in goats treated with GnRH $(12 \cdot 7 \pm 1 \cdot 3)$ than in those that received PMSG only $(9.7 \pm 1 \cdot 1 ; P<0.05)$. Out of 47 of the females in Exp. 1, 43 had one or more corpora lutea at laparoscopy $24 \mathrm{~h}$ after withdrawal of progestagen. These early corpora lutea were associated with an increased concentration of plasma progesterone during the periovulatory period. Experiment 3 provided evidence that these corpora lutea arose before the withdrawal of progestagen-impregnated sponges.
\end{abstract}

Keywords: goats; PMSG; ovulation; laparoscopy; progesterone

\section{Introduction}

Precision of timing of superovulation is necessary for studying early embryonic development, and for collection of pronuclear oocytes for injection of DNA in order to produce transgenic animals. Knowledge of the time of ovulation also permits the timing of artificial insemination to approximate the time of ovulation, with a consequent increase in fertility (Ritar et al., 1987). The time of superovulation has not been reported for goats. In sheep the timing of superovulation is extended unless gonadotrophin releasing hormone $(\mathrm{GnRH})$ is administered during the follicular phase (Walker et al., 1986).

The aim of the present experiments was to determine the time of ovulation in goats treated with superovulatory doses of PMSG with or without the subsequent administration of GnRH.

\section{Materials and Methods}

\section{Animals}

The experiments were conducted in autumn (April and May), using feral goats that had been kept on pasture at our Rye research station for at least 4 months. Before the experiment the animals had grazed green pasture. The animals were fasted from $12 \mathrm{~h}$ before laparoscopy began, until the time of the last laparoscopic examination. They had access to water between laparoscopic examinations.

\section{Experimental procedure:}

Experiment 1 . Oestrus was synchronized in 47 females by using intravaginal progestagen-impregnated sponges (60 mg medroxyprogesterone acetate; Repromap; Upjohn, Melbourne, Australia) for 16 days. Each female then 
received 1200 i.u. PMSG (Pregnecol: Heriot Agvet, Melbourne) intramuscularly, 2 days before withdrawal of sponges, and 22 of the goats were further treated with $50 \mu \mathrm{g}$ GnRH (Fertagyl; Intervet, Lyppard Chemical Co., Melbourne), intramuscularly, $20 \mathrm{~h}$ after withdrawal of sponges.

The ovaries of all nannies were examined by laparoscopy at 6-h intervals, beginning $24 \mathrm{~h}$ after withdrawal of sponges. Observations ceased for individual goats when the number of corpora lutea did not increase between consecutive observations. Blood samples were collected from the jugular vein into heparinized tubes at 9-h intervals from 18 to $45 \mathrm{~h}$ after sponges were withdrawn. The plasma was separated by centrifugation and stored at $-20^{\circ} \mathrm{C}$ until assayed for progesterone.

Experiment 2. This was a repeat of the first experiment, using different goats, except that laparoscopy began $45 \mathrm{~h}$ after withdrawal of sponges, and continued at 12-h intervals, and no blood was collected: 24 goats received PMSG, and 24 received PMSG and GnRH.

Experiment 3. This was conducted to determine whether PMSG caused ovulation before the withdrawal of progestagen-impregnated sponges: 19 goats received intravaginal sponges for 16 days, and 10 of these 19 received 1200 i.u. PMSG after 14 days. The ovaries of all nannies were examined after sponges has been inserted for 14 days, immediately before the administration of PMSG, and again 2 days later.

\section{Laparoscopy}

All laparoscopic examinations were carried out under local anaesthesia (Lignocaine, 2\%, Troy Laboratories, Sydney). In Exp. 1 generally I or 2, but up to 6, corpora lutea were observed at the first examination in 43 of the 47 does, $24 \mathrm{~h}$ after sponges were withdrawn. With the exception of 1 goat, these corpora lutea did not look like fresh ovulation points because of their larger size, deeper red colour, and less distinct ovulation point, but rather were considered to be at least 1 day old (Oldham \& Lindsay, 1980). Such corpora lutea were not included in the calculation of time to start of superovulation in Exps 1 or 2.

\section{Progesterone assay}

Plasma progesterone concentrations were determined by radioimmunoassay using a direct solid-phase ${ }^{125}$ I assay employing human antiserum (Coat-a-Count; Diagnostic Products Corporation, Los Angeles, CA, U.S.A). The sensitivity of the assay system was $0.05 \mathrm{ng} \mathrm{ml}$, and cross-reactivity with other steroids was $<1 \%$, except for 11 -deoxycortisol $(2.4 \%)$ and $20 \alpha$-dihydroprogesterone $(2.0 \%)$. All concentrations were determined in a single assay, in which the intra-assay coefficient of variation was $2 \cdot 3 \%$.

\section{Statistical analyses}

The time to start of ovulation and that to occurrence of individual ovulations were taken to be the midpoint between the time between the first time an ovulation point was observed and the time of the immediately preceding observation. Proportions of goats ovulating were compared using G tests (Sokal \& Rohlf, 1981), progesterone concentrations were compared using a Mann-Whitney test (Siegel, 1956) and ovulation rates were compared using Student's $t$ test.

\section{Results}

\section{Experiment 1}

The time to start of superovulation was protracted in nannies treated with PMSG alone, having begun by $30 \mathrm{~h}$ after sponge withdrawal in 1 doe, and not having begun in 9 goats at the final observation at $54 \mathrm{~h}$ (Fig. 1). The administration of GnRH improved the synchrony of ovulation, as shown by the increased proportion of goats that had ovulated by the final observation at $54 \mathrm{~h}$ (20/22 for those treated with GnRH compared to $16 / 25$ for those receiving PMSG alone $(P<0 \cdot 05)$. The precision in timing of ovulation after treatment with $\mathrm{GnRH}$ was emphasized when the time of appearance of each ovulation was determined (Fig. 2), with $91 \%$ of ovulations occurring between 36 and $48 \mathrm{~h}$. The mean ( \pm s.d.) time of appearance of each ovulation was $41 \cdot 6 \pm 3.8 \mathrm{~h}$ after sponge withdrawal in the GnRH-treated females. As shown in Fig. 2, 37 ovulations were present at the first inspection, $24 \mathrm{~h}$ after withdrawal of sponges. 


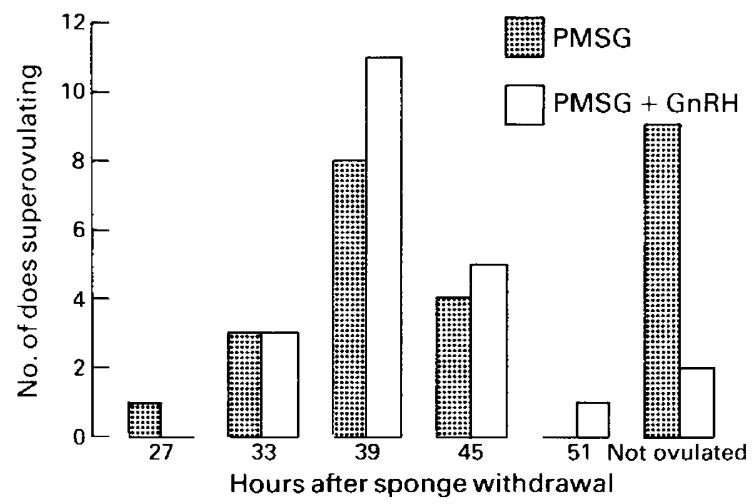

Fig. 1. The time to start of superovulation relative to sponge withdrawal in goats treated with 1200 i.u. PMSG $(\mathrm{N}=25)$ or with 1200 i.u. PMSG and $50 \mu \mathrm{g} \mathrm{GnRH}(\mathrm{N}=22)$ in Exp. 1.

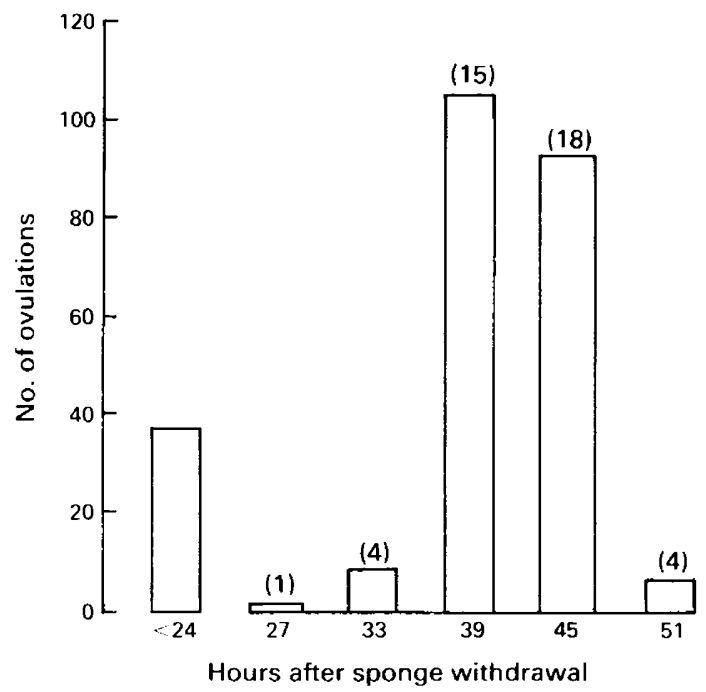

Fig. 2. Time of appearance of ovulation points in 22 goats treated with 1200 i.u. PMSG and $50 \mu \mathrm{g} \mathrm{GnRH}$ in Exp. 1. Ovulations present at $24 \mathrm{~h}$ were not considered to be part of the superovulatory response. The numbers of goats contributing ovulations are in parentheses.

\section{Experiment 2}

Only 2 does (neither of which had received GnRH) had not begun to ovulate by the time of first laparoscopy, $45 \mathrm{~h}$ after sponge withdrawal. One of these does had ovulated at the next observation, at $57 \mathrm{~h}$, and the other at $69 \mathrm{~h}$. Nevertheless, the improved synchrony of ovulation achieved by GnRH was again evident, as $91 \%$ of ovulations were present at the 45 -h observation in the GnRH treated group, compared to only $64 \%$ in controls (Fig. 3). The distributions in time of appearance of individual ovulations differed significantly between females that had or had not received GnRH $(P<0.001)$. Nannies treated with GnRH also had a higher mean ( \pm s.e.m.) ovulation rate than did control females $(12.7 \pm 1.3$ compared to $9.7 \pm 1 \cdot 1 ; P<0.05)$. 


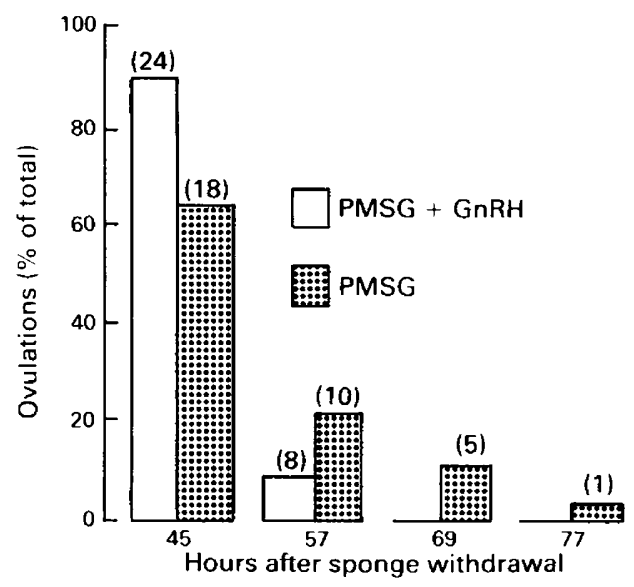

Fig. 3. The time of appearance of ovulation points in goats treated with 1200 i.u. PMSG $\pm 50 \mu \mathrm{g} \mathrm{GnRH}$ in Exp. 2. The numbers of goats contributing ovulations are in parentheses.

\section{Experiment 3}

No corpora lutea were observed on Day 14, just before the administration of PMSG. Two days later $8 / 10$ females that had received 1200 i.u. PMSG had ovulated whereas none of the untreated females had done so $(P<0.001)$.

\section{Progesterone concentrations}

Concentrations of plasma progesterone were determined in Exp. 1 for 3 goats in which no corpora lutea were observed $24 \mathrm{~h}$ after withdrawal of sponges, and 9 randomly selected goats in which CL were observed. The concentration of progesterone was generally greater in the does that did have corpora lutea present (Fig. 4) with the difference between the 2 means being significant $(P<0.05) 27 \mathrm{~h}$ after sponges were withdrawn.

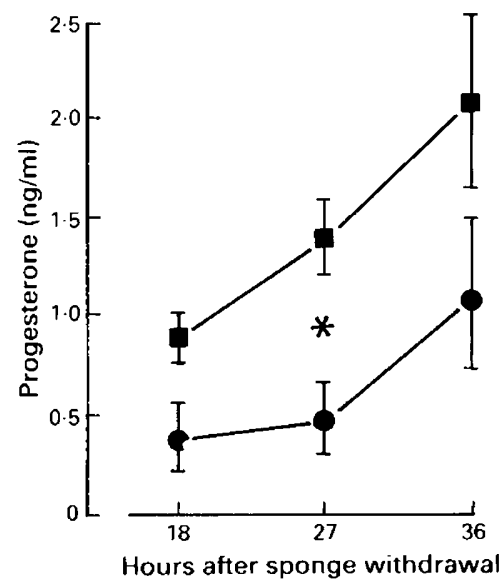

Fig. 4. Progesterone concentrations in 9 nanny goats in which ovulations were present $(\boldsymbol{\square})$ or 3 in which they were absent $(\bullet), 24 \mathrm{~h}$ after sponge withdrawal. ${ }^{*} P<0.05$. 


\section{Discussion}

Taken together, the results of Exps 1 and 2 indicate that superovulation takes place over about a 48-h period in goats treated with PMSG, having started as early as $30 \mathrm{~h}$ after withdrawal of sponges in Exp. 1, and with fresh ovulation points being observed at $77 \mathrm{~h}$ in Exp. 2. Most of the ovulations probably appear between 36 and $60 \mathrm{~h}$ after sponge withdrawal in goats treated only with PMSG because in the 25 females in Exp. 1 only 16 corpora lutea were present by $36 \mathrm{~h}$, and in 24 nannies in Exp. 2 only 26 of a total of 193 corpora lutea were not observed by $57 \mathrm{~h}$.

GnRH improved the synchrony of ovulation in Exps 1 and 2. Because superovulation was completed in all but 2 goats treated with GnRH at $54 \mathrm{~h}$ in Exp. 1, the distribution of ovulations presented in Fig. 2 is presumably representative of a complete population. A similarly synchronous distribution has been described for superovulated ewes treated with GnRH (Walker et al., 1986). The mean ( \pm s.d.) time of appearance of each ovulation of $41.6 \pm 3.8 \mathrm{~h}$ provides a useful reference point around which artificial insemination and ova or embryo recovery can be timed.

Our decision to terminate our observations in Exp. 1 also appears justified in terms of the quality of the data that further observation would have provided, as the stress of repeated laparoscopy had either delayed or inhibited ovulation in some of the goats in Exp. 1. This is shown by the $13 / 47$ goats that had not begun to superovulate by $48 \mathrm{~h}$ in Exp. 1, whereas only 2/48 goats had not begun to superovulate by $45 \mathrm{~h}$ in Exp. $2(P<0.01)$. In Exp. 1, no goats treated with PMSG alone began ovulating beyond $48 \mathrm{~h}$ after sponge withdrawal (Fig. 1), i.e. $24 \mathrm{~h}$ after laparoscopy began. If ovulation occurs $24 \mathrm{~h}$ after the onset of the LH surge, as it does in sheep (Cumming et al., 1973), and appears likely to in goats (Ritar et al., 1984), then it seems probable that no LH surge began after the time of the first laparoscopic examination.

The high proportion of goats that ovulated after PMSG injection but before withdrawal of progestagen-impregnated sponges was surprising. While progesterone can inhibit tonic LH secretions at high concentrations in nanny goats (Sutherland, 1987b) it appeared to have no effect on concentrations that approximate those found during the luteal phase of ewes (Sutherland, 1987a). These findings led Sutherland (1987b) to suggest that a dose of progestagen sufficient to control the oestrous cycle of sheep may not be adequate in goats. Our observation lends weight to this suggestion.

The occurrence of ovulations before the withdrawal of sponges has a number of implications for fertility. First, the eggs released are probably no longer fertilizable by the time spermatozoa are present in the oviducts, and therefore premature ovulation will be a cause of fertilization failure. Second, these early ovulations presumably result from an increase in circulating LH that must also occur while the sponges are in place. Such LH surges would presumably exacerbate the problem of premature activation of oocytes that has been observed in PMSG-treated sheep by Moor et al. (1985), who considered this phenomenon to be due to the predominantly LH-like activity of PMSG. Finally, the early ovulations led to elevated concentrations of plasma progesterone during the peri-ovulatory period, which may have deleterious effects on the transport of spermatozoa and oocytes.

This work was funded by Embryotechnology Australia Pty Ltd and was carried out at their research station. We thank Miss B. Scher for assistance.

\section{References}

Cumming, I.A., Buckmaster, J.M., Blockey, M.A. de B., Goding, J.R., Winfield, C.G. \& Baxter, R.W. (1973) Constancy of interval between luteinizing hormone release and ovulation in the ewe. Biol. Reprod.9,24-29. Moor, R.M., Osborn, J.C. \& Crosby, I.M. (1985)
Gonadotrophin-induced abnormalities in sheep oocytes after superovulation. J. Reprod. Fert. 74, $167-172$.

Oldham, C.M. \& Lindsay, D.R. (1980) Laparoscopy in the ewe: a photographic record of the ovarian activity 
of ewes experiencing normal or abnormal oestrous cycles. Anim. Reprod. Sci. 3, 119-124.

Ritar, J.A., Maxwell, W.M.C. \& Salamon, S. (1984) Ovulation and LH secretion in the goat after intravaginal progestagen sponge-PMSG treatment. $J$. Reprod. Fert., 72, 559-563.

Ritar, A.S., Ball, P., Black, T., Jackson, R.B., O'May, P., Heazlewood, F. \& Graham G. (1987) AI of cashmere goats: effect of CIDR or sponge, dose of frozen-thawed semen, and time of cervical or laparoscopic insemination. Proc. Aust. Soc. Reprod. Biol. 19, 28 , Abstr.

Siegal, S. (1956) Non-parametric Statistics for the Behavioral Sciences. McGraw-Hill Kogakusha Ltd, Tokyo.

Sokal, R.R. \& Rohlf, F.J. (1981) Biometry, 2nd edn. W. H. Freeman and Company, San Francisco.
Sutherland, S.R.D. (1987a) Effects of oestradiol and progesterone on $\mathrm{LH}$ secretion during anoestrus and the breeding season in ovariectomized Angora-cross does. Proc. 4th Asian Australasian Animal Production Congress, Hamilton, N.Z.P. 230, Abstr.

Sutherland, S.R.D. (1987b) Progesterone concentration and pulsatile LH secretion during normal oestrous cycles in Angora-cross does. Proc. 4th Asian Australasian Animal Production Congress, Hamilton, N.Z.P. 246, Abstr.

Walker, S.K., Smith, D.H. \& Seamark, R.F. (1986) Timing of multiple ovulations in the ewe after treatment with FSH or PMSG with and without GnRH.J. Reprod. Fert., 77, 135-142.

Received 3 November 1987 